\title{
Lipopolysaccharide Exposure Modifies High Tidal Volume Ventilation-Induced Proinflammatory Mediator Expression in Newborn Rat Lungs
}

\author{
MATTHIAS ROTH-KLEINER, ROSS RIDSDALE, LEI CAO, MACIEJ KULISZEWSKI, IRENE TSEU, COLIN MCKERLIE, \\ AND MARTIN POST
}

\begin{abstract}
Lung Biology Research Program [M.R.-K., R.R., L.C., M.K., I.T., M.P.], The Hospital for Sick Children Research Institute, Toronto, Ontario M5G1X8, Canada; Department of Laboratory Medicine and Pathobiology [C.M., M.P.], University of Toronto, Toronto, Ontario M5G 1L5, Canada; Department of Pediatrics [M.P.], University of Toronto, Toronto, Ontario M5G1X8, Canada; Division of Neonatology [M.R.-K.], Centre Hospitalier Universitaire Vaudois, CH-1011 Lausanne, Switzerland
\end{abstract}

\begin{abstract}
Infection/inflammation and mechanical ventilation have both independently been shown to increase cytokine/chemokine levels in lung tissue and blood samples of premature patients. Little is known about the combined effect of systemic inflammation and mechanical ventilation on cytokine expression in the lung. We tested whether pre-existing inflammation induced by lipopolysaccharide (LPS) exposure would modify cytokine/chemokine response in newborn rat lungs to high tidal volume ventilation (HTVV). Newborn rats were randomly assigned to four groups: groups I and II (saline); groups III and IV: $3 \mathrm{mg} / \mathrm{kg}$ LPS. Groups II and IV were $24 \mathrm{~h}$ later subjected to $3 \mathrm{~h}$ of ventilation with a tidal volume of $25 \mathrm{~mL} / \mathrm{kg}$. HTVV alone increased IL-1 $\beta$, IL-6 and the chemokine (C-X-C motif) ligand 2 (CXCL2) mRNA expression. Although the cytokine response to LPS alone had disappeared after $24 \mathrm{~h}$, the combination of LPS pretreatment and HTVV significantly increased the expression of IL- 6 and IL- $1 \beta$ mRNA when compared with HTVV alone. TNF- $\alpha$ expression was increased neither by HTVV alone nor in combination with LPS. IL-6 protein content in bronchoalveolar lavage increased due to the combined treatment. Thus, a subtle pre-existing inflammation combined with HTVV amplifies the proinflammatory cytokine/chemokine expression in the newborn rat lung compared with HTVV alone. (Pediatr Res 61: 191-196, 2007)
\end{abstract}

$\mathrm{B}$ ronchopulmonary dysplasia (BPD) remains a major healthcare problem in neonatology (1). It affects mainly premature babies which require mechanical ventilation and high concentrations of oxygen early in life. Risk is enhanced with an associated infection/inflammation, e.g., chorioamnionitis or sepsis $(2,3)$. The inflammation in BPD is characterized by recruitment of neutrophils from blood into the injured lung

Received June 5, 2006; accepted September 26, 2006.

Correspondence: Martin Post, Ph.D., Lung Biology Research Program, The Hospital for Sick Children, 555 University Avenue, Toronto, Ontario, M5G 1X8; e-mail: martin. post@sickkids.ca

Supported by: Operating grant (MOP-15272) from the Canadian Institute of Health Research and infrastructure grant (CCURE) from the Canadian Foundation for Innovation. M. Roth-Kleiner is recipient of a Swiss Neonatology Research Award and is supported by the Fonds de perfectionnement et de pediatrie du CHUV, Lausanne, Switzerland, the Foundation Eugenio Litta, Switzerland and the Foundation Pittet, Lausanne, Switzerland and the Swiss Life Foundation, Switzerland. M. Post is the holder of a Canadian Research Chair in Respiration.

DOI: 10.1203/01.pdr.0000252437.51779.21 tissue that is directed by a group of proinflammatory polypeptides, the chemokines. A subclass of chemokines, the glutamyl-leucyl-arginine (ELR) motif containing CXC chemokines, incuding IL-8 and growth regulated oncogene (GRO), has been shown to be critical for neutrophil binding and chemotactic functions (4). Increased levels of proinflammatory cytokines/chemokines such as IL- 8 , IL- 6 and IL- $1 \beta$ in amniotic fluid and bronchoalveolar lavage fluid (BALF) of premature infants have been proposed to be prognostic indicators for developing BPD (5-7). Proinflammatory cytokines/ chemokines are up-regulated by different stimuli, such as mechanical, hyperosmotic or oxidative cellular stress, bacterial or viral products, or other proinflammatory cytokines $(8-10)$. A few studies in adult rodents have recently investigated the combined effect of pre-existing inflammation and mechanical ventilation on pulmonary cytokine/chemokine expression and injury (11-13). The combination of mechanical ventilation and local (lung) or systemic inflammation showed an increased risk for lung injury. Moreover, expression of the chemokine CXCL2 (GRO2/MIP2, macrophage inflammatory protein 2), a functional rodent homolog of human IL-8, was increased in lungs when mechanical ventilation was combined with pre-existing inflammation $(11,13)$. To date, no studies have reported the effect of mechanical ventilation of immature lungs superimposed on systemic inflammation. In the clinical realm, the setting of premature babies exposed to inflammation who need positive pressure ventilation to treat respiratory distress occurs frequently. To mimic this clinical situation we created an in vivo newborn rat model with systemic exposure to LPS before the induction of high tidal volume ventilation (HTVV) $24 \mathrm{~h}$ later. Rat lungs at birth are in the saccular stage of lung development which corresponds to the lung development stage of very premature patients (14). In contrast to humans, alveolarization in rats occurs exclusively postnatally (between P4 and P21). Using this newborn rat model of alveolar development, we observed that a systemic exposure to LPS combined with HTVV amplifies the proinflammatory

\footnotetext{
Abbreviations: BALF, bronchoalveolar lavage fluid; BPD, bronchopulmonary dysplasia; CXCL-, chemokine (C-X-C motif) ligand; HTVV, High tidal volume ventilation; LPS, Lipopolysaccharide
} 
cytokine/chemokine expression seen with HTVV alone, thereby likely enhancing the risk for ventilator-induced lung injury and BPD.

\section{MATERIALS AND METHODS}

Animals. Newborn Wistar rats (postnatal day 3-6) (Charles River, Oakville, Quebec, Canada) were randomly assigned to two different pretreatment strategies consisting of a single intraperitoneal injection of either 3 $\mathrm{mg} / \mathrm{kg}$ body weight of lipopolysaccharide (LPS) from E. coli serotype 026:B6 (Sigma Chemical Co., Aldrich, St. Louis, MO) or the same volume of $0.9 \%$ $\mathrm{NaCl}$. All litters were reduced to 12 pups at postnatal day 1 . Weight gain was assessed by measuring weight at postnatal day 3 prior and 24h after LPS or $\mathrm{NaCl}$ injection and compared with noninjected controls. The animals were further subdivided 24h after injection of LPS or saline into ventilation and nonventilation groups. Each of the resulting four groups consisted of 11-13 animals and were labeled: Group I) pretreatment with saline, no ventilation; Group II) pretreatment with saline and high tidal volume ventilation (HTVV); Group III) pretreatment with LPS and no ventilation; and Group IV) pretreatment with LPS and HTVV. Before ventilation, the animals were anesthetized by intraperitoneal injection of a mixture of ketamine (Pfizer, Kirkland, Canada) $50 \mathrm{mg} / \mathrm{kg}$ body weight, Acepromazine (Vétoquinol Inc., Lavaltrie, Canada) $1 \mathrm{mg} / \mathrm{kg}$ body weight, and atropine (MTC Pharmaceuticals, Cambridge, Canada) $76.5 \mu \mathrm{g} / \mathrm{kg}$ body weight. Additional anesthetic was administered throughout the protocol as needed. A tracheotomy was performed and a $22 \mathrm{G}$ cannula inserted into the trachea, firmly secured with a 4.0 silk suture to prevent air leak and connected to a rodent ventilator (Rodent Ventilator, Voltek Enterprises Inc, Toronto, Canada) (15). During the entire protocol, the animals were continuously monitored by ECG (Hewlett Packard, Palo Alto, $\mathrm{CA})$ and a rectal temperature probe $(\mathrm{B}+\mathrm{K}$ Precision Corp, Yorba Linda, $\mathrm{CA})$. Rectal temperature was maintained at $36-37^{\circ} \mathrm{C}$ by placing the animals on a thermal blanket.

Institutional review. Approval for the study was obtained from the Animal Care Review Committee of the Hospital for Sick Children Research Institute. All animal procedures were conducted according to guidelines of the Canadian Council for Animal Care.

Mechanical ventilation. The animals of Groups II and IV were ventilated for $3 \mathrm{~h}$ with a tidal volume $\left(\mathrm{V}_{\mathrm{T}}\right)$ of $25 \mathrm{~mL} / \mathrm{kg}$ body weight, a respiratory rate of 60/min, PEEP (Positive End Expiratory Pressure) $=0 \mathrm{~cm} \mathrm{H}_{2} \mathrm{O}$ and an inspiratory/expiratory ratio of 1:1. Dynamic compliance of the total respiratory system was calculated from the ventilator $\mathrm{V}_{\mathrm{T}}$ (measured as expiratory volume by an internal pneumotachometer) and the difference between peak inspiratory pressure and PEEP (measured by the internal pressure transducer). Compliance values were further normalized to body weight. Blood gases and $\mathrm{pH}$ were assayed in arterial blood collected from the carotid artery at the end of ventilation in 6 animals per ventilation group (ABL 500, Radiometer Medical, Copenhagen, Denmark). In all animals, the left lung lobe was isolated, excised, and snap-frozen in liquid nitrogen and stored at $-70^{\circ} \mathrm{C}$ for gene expression measurements. The right lung was either fixed by immersion in $10 \%$ neutral buffered formalin for histologic processing and evaluation or bronchoalveolar lavage was performed.

RNA isolation and realtime RT-PCR. The frozen left lobe was homogenized in Trizol ${ }^{\circledR}$ (Invitrogen Canada Inc, Burlington, Canada) and total RNA was extracted according to the manufacturer's protocol. Total RNA was treated with DNAse $I^{\circledR}$ (Invitrogen Canada Inc, Burlington, Canada) at $37^{\circ} \mathrm{C}$ to remove residual genomic DNA. Total RNA was reverse transcribed using Superscript II reverse transcriptase ${ }^{\circledR}$ (Invitrogen Canada Inc, Burlington, Canada) and random hexamers (Applied Biosystems, Foster City, CA). cDNA was quantified in a 7700 Sequence Detector (Applied Biosystems, Foster City, CA) using $40 \mathrm{ng}$ of total cDNA for tenascin C (TNC), tropoelastin, CXCL2 (GRO2/MIP2), T1 $\alpha$, vascular endothelial growth factor (VEGF) and VEGF-receptor 2 (VEGFR2) and $100 \mathrm{ng}$ of cDNA for IL-6 (IL-6), IL-1beta $(\mathrm{IL}-1 \beta)$ and tumor necrosis factor alpha (TNF- $\alpha$ ). Amplification was performed with Amply Taq Gold polymerase (Applied Biosystems, Foster City, Canada), using TaqMan primers and probes (Applied Biosystems, Foster City, Canada) for the target genes (Table 1) and Assays on Demand ${ }^{\circledR}$ for VEGF and VEGFR2 (Applied Biosystems, Foster City, Canada) and 18S (Applied Biosystems, Foster City, Canada) as recently described (16). For relative quantification, PCR signals were compared between groups after normalization using $18 \mathrm{~S}$ as an internal reference. Fold change was calculated according to Livak and Schmittgen (17).

Cytokine protein measurement in bronchoalveolar lavage fluid (BALF). Bronchoalveolar lavage was performed through a $22 \mathrm{G}$ catheter inserted into the trachea by a tracheotomy as recently described (18) and adapted for newborn animals (19). Briefly, the lungs were infused with $1 \mathrm{~mL}$ of PBS
Table 1. Taqman primer and probe sequences of rat cytokines and alveolarization markers

\begin{tabular}{lll}
\hline Gene probe & Primer/ & \multicolumn{1}{c}{ Sequence } \\
\hline IL-1 $\beta$ & Forward & CTTGTCGAGAATGGGCAGTCT \\
& Reverse & TGTGCCACGGTTTCTTATGG \\
& Probe & AAGCCTTTGTCTCTGCCAAGTCAGGTCT \\
IL-6 & Forward & CCCACCAGGAACGAAAGTCA \\
& Reverse & GGCAACTGGCTGGAAGTCTCT \\
& Probe & CTCCATCTGCCCTTCAGGAACAGCTATG \\
TNF- $\alpha$ & Forward & GCATGATCCGAGATGTGGAA \\
& Reverse & AGACACCGCCTGGAGTTCTG \\
& Probe & CAGAGGAGGCGCTCCCCAAAAAGA \\
CXCL2 & Forward & CCAACCATCAGGGTACAGGG \\
& Reverse & GGGTCGTCAGGCATTGACA \\
& Probe & TGTTGTGGCCAGTGAGCTGCGC \\
TNC & Forward & ACCGTGGATGGGACGGATA \\
& Reverse & GGCAATCACACTGACGTGGTA \\
& Probe & AGACCCGACTGGTGAGGCTCACCC \\
Tropoelastin & Forward & TGGAGCCCTGGGATATCAAG \\
& Reverse & GTTGATGAGGTCGCGAGTCA \\
& Probe & CTTTGGGAAATCTTGTGGCCGGAAG \\
T1 $\alpha$ & Forward & GCCATCGGTGCGCTAGAA \\
& Reverse & AGACCTGGGTTCACCATGTCA \\
& Probe & TCTTGTGACCCCGGGTCCAGGA
\end{tabular}

IL, interleukin; TNF, tumor necrosis factor; CXCL2, chemokine (C-X-C motif) ligand; TNC, tenascin $\mathrm{C}$.

(PBS), followed by withdrawal and reinfusion two more times. The lavage material recovered from each animal $(0.3-0.4 \mathrm{~mL}$ average) did not differ between the four groups. Cytokines/chemokines were measured in the BALF samples using multiplex immunoassays for Luminex technology from Linco Research Inc. (St. Charles, MO) as previously described (18).

Histology. In 3 nonlavaged animals per treatment group (control group $n=2$ ), the left lung was ligated and extracted for RNA measurement while the right lung was infused with $4 \%$ paraformaldehyde (PFA) in PBS with a constant pressure of $20 \mathrm{~cm} \mathrm{H}_{2} \mathrm{O}$ over two minutes to equalize filling pressure over the entire right lung. Under these constant pressure conditions the cannula was removed and the trachea immediately ligated. The excised lung tissue was immersed in 4\% PFA in PBS overnight and then dehydrated in an ethanol/xylene series and embedded in paraffin (25). Sections of $5 \mu \mathrm{m}$ were then stained with hematoxilin and eosin for light microscopic evaluation and scoring. A semi-quantitative analysis of inflammatory cell infiltration was assessed as previously described $(20,21)$ using the following three parameters. Airspace Score: the presence of inflammatory cells in interalveolar septa; and the presence of inflammatory cells within alveoli; and Airway Score: peribronchiolar infiltration of inflammatory cells. Each parameter was evaluated semi-quantitatively, using a five-grade scale (normal $=0$; questionable change $=1$, minimal change $=2$; moderate change $=3$; and marked change $=4)$. All histopathological examinations were conducted by a pathologist (CMK) blinded to group allocation.

Statistical analysis. Data are expressed as mean \pm SE (SE) or median \pm quartiles (nonparametric data). T-test or analysis of variance (ANOVA) followed by Student-Newman-Keuls testing was used. ANOVA on ranks was used for the semi-quantitative analysis of inflammatory cell infiltration. Significance was set at $p<0.05$.

\section{RESULTS}

Lps timing. Pilot studies revealed that an intraperitoneal injection of $3 \mathrm{mg} / \mathrm{kg}$ LPS induced cytokine (IL-6) and chemokine (CXCL2) expression in lungs of P3 newborn rats without affecting survival. Administration of higher dosages of LPS significantly increased mortality. To determine the influence of the $3 \mathrm{mg} / \mathrm{kg}$ LPS treatment on the whole organism, weight gain was evaluated on P4, 24h after either LPS injection $(n=6)$, the same volume of $0.9 \% \mathrm{NaCl}(n=5)$ or no injection $(n=20)$. LPS injection resulted in a significantly reduced mean weight gain in $24 \mathrm{~h}[10.7 \%$ in LPS treated rats 


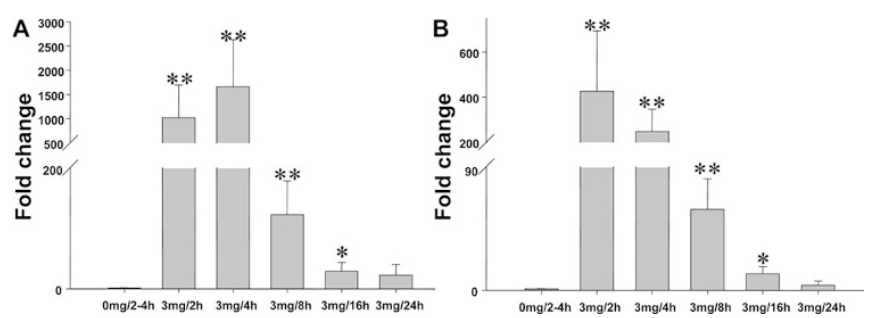

Figure 1. Temporal expression pattern of (A) IL-6 (IL-6) and (B) CXCL2 mRNA in newborn rat lung tissue after intraperitoneal lipopolysaccharide (LPS) injection of $3 \mathrm{mg} / \mathrm{kg}$ body weight. Controls were injected with saline. Data are relative values compared with control animals. Data are mean $\pm \mathrm{SE}$, $n=3-6$ animals per group; $* * p<0.01 ; * p<0.05$.

versus $17.9 \%$ in $\mathrm{NaCl}$ treated rats $(p<0.001)$ versus $17.8 \%$ in pups without any injection $(p<0.001)$ ]. To determine the temporal pattern of cytokine/chemokine expression we measured IL-6 and CXCL2 mRNA in lung tissue 2, 4, 8, 16, or $24 \mathrm{~h}$ after the intraperitoneal injection of $3 \mathrm{mg} / \mathrm{kg}$ LPS and compared it to saline-injected controls $(n=3-6$ animals per time point). IL-6 and CXCL2 mRNA levels peaked 2-4 $\mathrm{h}$ after LPS injection, fell thereafter and were statistically not different from saline controls $24 \mathrm{~h}$ after injection (Fig. 1). To simulate a systemically induced low-grade inflammation, we choose for all the following experiments a time interval of $24 \mathrm{~h}$ between the administration of $3 \mathrm{mg} / \mathrm{kg}$ LPS and HTVV.

Ventilation. There was no significant difference between the two ventilation groups II ( $\mathrm{NaCl} ; n=6)$ and IV (LPS; $n=6)$ after $3 \mathrm{~h}$ of HTVV regarding $\mathrm{pH}$ (II: 7.53 versus IV: 7.51 ), $\mathrm{pCO}_{2}$ (II: $29.5 \mathrm{~mm} \mathrm{Hg}$; IV: $29.8 \mathrm{~mm} \mathrm{Hg}$ ) and $\mathrm{pO}_{2}$ (II: $55.8 \mathrm{~mm} \mathrm{Hg}$; IV: $49.6 \mathrm{~mm} \mathrm{Hg}$ ). Dynamic compliance increased significantly in both groups within the first 5-10 min of ventilation due to lung recruitment by the high tidal volumes and then remained stable for the rest of the experiment (Fig. 2). There was no significant difference in dynamic compliance between the two groups.

Cytokine mRNA expression. HTVV alone increased mRNA expression of IL-6 by 7.2-fold, CXCL2 by 7.3-fold and IL- $1 \beta$ by 1.8 -fold compared with controls (Fig. $3 A-C$, Group II versus I). TNF- $\alpha$ mRNA expression remained unchanged (Fig. 3D). LPS alone did not show a significant change in IL-6, CXCL2, IL- $1 \beta$ and TNF- $\alpha$ mRNA expression $24 \mathrm{~h}$ after injection when compared with saline injected controls (Fig. 3A-D, group I versus III). The combination of LPS pretreatment and HTVV increased IL- 6 and IL- $1 \beta$ mRNA expression by a factor of 10.5 and 2.5 , respectively, compared with the HTVV alone group (Fig. 3A,C). Although not significant, CXCL2 mRNA expression showed a similar trend (Fig. 3B).

Expression of factors implicated in alveolarization. To evaluate the effect of the treatments on alveolarization, we also analyzed the mRNA expression of factors known to have an impact on alveolar formation (22). No significant changes were observed for the type I cell marker T $1 \alpha$ and the extracellular matrix proteins tenascin-C (TNC) and tropoelastin in any of the four treatment groups (Fig. $4 A-C$ ). While no change in vascular endothelial growth factor (VEGF) gene expression was observed (Fig. 4D), its receptor (VEGFR2) showed a trend to reduced expression by HTVV alone, but this difference was attenuated by LPS injection (Fig. 4E).

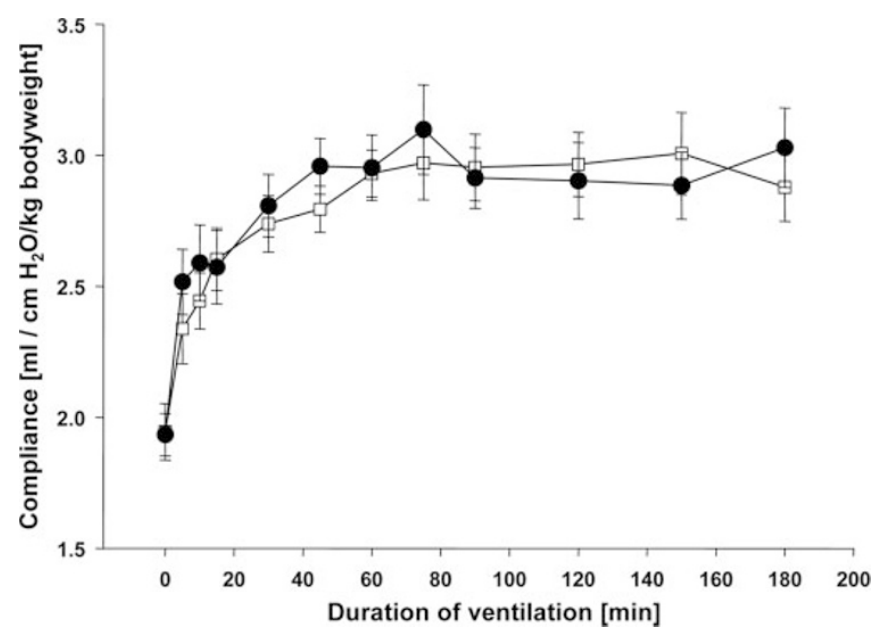

Figure 2. Dynamic compliance of the respiratory system of newborn rats ventilated in vivo with high tidal volumes after treatment with or without LPS and a ventilator rate of $60 / \mathrm{min}$. Data are mean \pm SE; $\square$ Group II $-\mathrm{NaCl}$ : pretreatment $(n=6)$; $\bullet$ : Group IV - LPS pretreatment $(n=5)$.
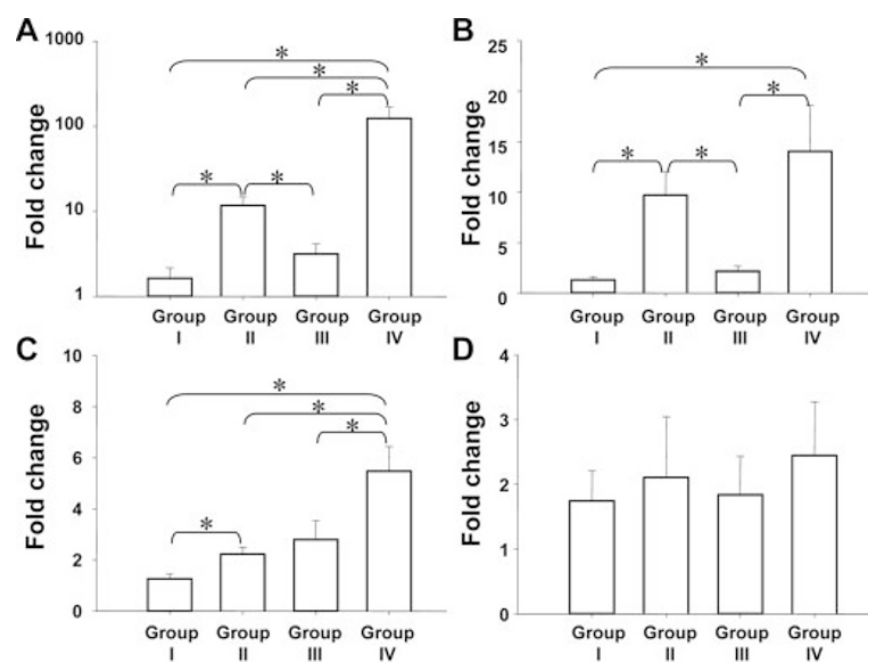

Figure 3. Cytokine mRNA expression in newborn rat lung tissue: (A) IL-6, (B) CXCL2, (C) IL-1 $\beta$, and (D) TNF- $\alpha$. Group I: pretreatment with $\mathrm{NaCl}$, no ventilation $(n=11)$, Group II: pretreatment with $\mathrm{NaCl}$ and ventilation $(n=$ 13), Group III: pretreatment with LPS, no ventilation $(n=12)$, Group IV: pretreatment with LPS and ventilation $(n=12)$. Relative values compared with control group I. All data are mean $\pm \mathrm{SE}(* p<0.05)$.

Cytokine protein in bronchoalveolar lavage fluid (BALF). LPS pretreatment did not influence the IL-6 protein content in BALF (Fig. 5A: group I versus III), but its concentration was significantly increased after $3 \mathrm{~h}$ of HTVV alone (group II: $34.01 \mathrm{pg} / \mathrm{mL}$ versus group I: $19.40 \mathrm{pg} / \mathrm{mL}$; Fig. $5 A$ ). The combination of LPS pretreatment and HTVV further increased IL-6 concentration in BALF (Group IV: $43.72 \mathrm{pg} / \mathrm{mL}$ ), although the increase did not reach significance. Because of a lack of a good rat CXCL2 (GRO2/MIP2) detection kit for the Luminex system, a closely related chemokine, CXCL1 (GRO1/ $\mathrm{KC}$ ), was measured. CXCL1 belongs to the ELR-CXC chemokine subfamily and also has chemoattractant effect on monocytes and neutrophils. While LPS alone did not change CXCL1 protein content in BALF, a trend to increased concentrations was seen in both ventilation groups (Group II and IV; Fig. 5B). No significant 


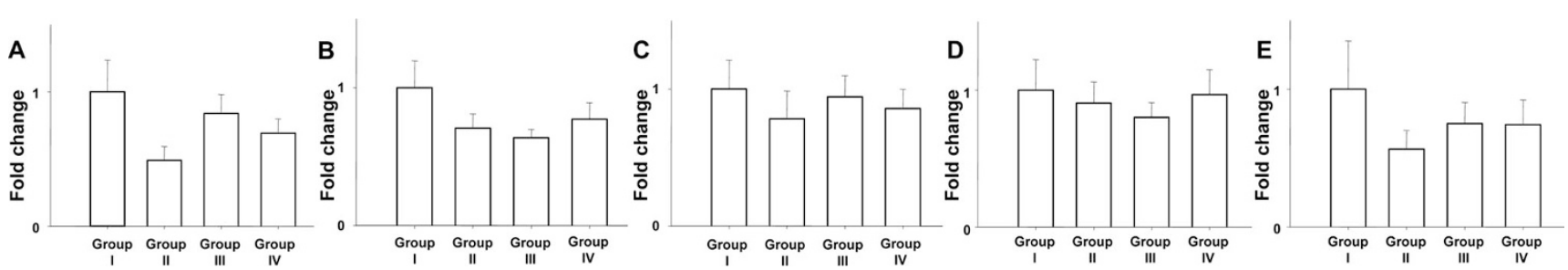

Figure 4. Gene expression of alveolarization markers in newborn rat lung tissue after LPS treatment and HTVV: $(A)$ T1 $\alpha,(B)$ TNC, $(C)$ tropoelastin, $(D)$ VEGF and $(E)$ VEGFR2. Group I: pretreatment with $\mathrm{NaCl}$, no ventilation $(n=11)$, Group II: pretreatment with $\mathrm{NaCl}$ and ventilation $(n=13)$, Group III: pretreatment with LPS, no ventilation $(n=12)$, Group IV: pretreatment with LPS and ventilation $(n=12)$. Relative values compared with control group I. All data are mean \pm SE.
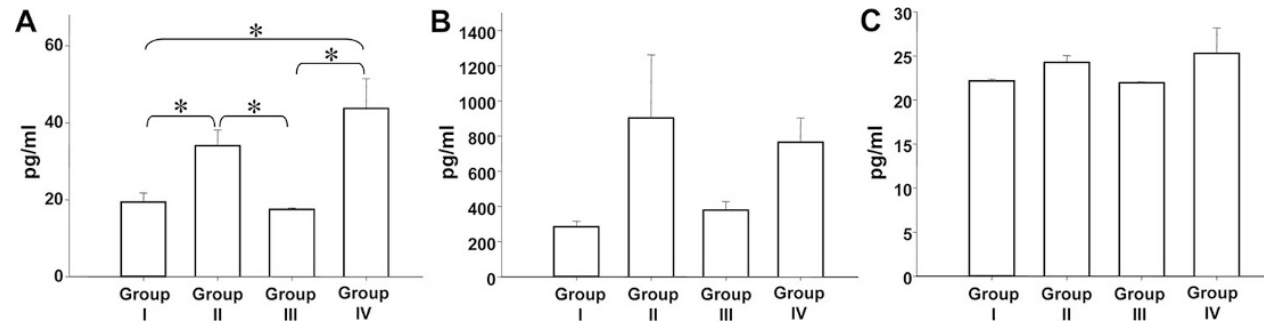

Figure 5. Cytokine protein content in bronchoalveolar lavage fluid of newborn rats [(A) IL-6, $(B)$ CXCL1, $(C)$ IL-1 $\beta$ ]. Group I: pretreatment with NaCl, no ventilation $(n=10)$; Group II: pretreatment with $\mathrm{NaCl}$ and ventilation $(n=11)$; Group III: pretreatment with LPS, no ventilation $(n=10)$; Group IV: pretreatment with LPS and ventilation $(n=9)$. All data are mean $\pm \mathrm{SE}(* p<0.05)$.
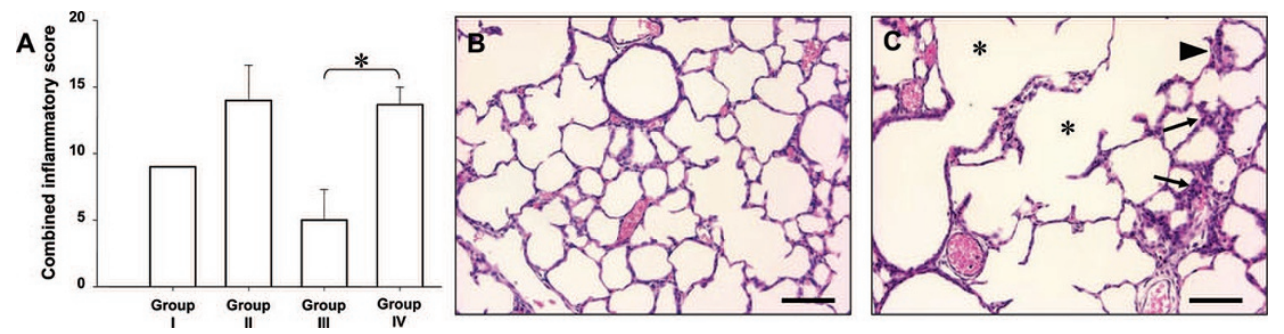

Figure 6. Histologic findings in newborn rat lung after LPS pretreatment and HTVV: (A) Combined airway and airspace inflammatory score related to the four treatment groups. Group I: pretreatment with $\mathrm{NaCl}$, no ventilation $(n=10)$; Group II: pretreatment with $\mathrm{NaCl}$ and ventilation $(n=11)$; Group III: pretreatment with LPS, no ventilation $(n=10)$; Group IV: pretreatment with LPS and ventilation $(n=9)$. Data are median \pm quartiles, ${ }^{*} p<0.05$. Newborn rat lung tissue sections stained with hematoxilin and eosin: $(B)$ Control lung (group I: pretreatment with $\mathrm{NaCl}$, no ventilation). (C) Moderate to marked patchy inflammatory cell aggregates within alveolar septae (arrows) and scattered cellular exudation into airspaces with concurrent hyperinflation (*), and amorphous eosinophilic material in airspaces (arrowhead) after pretreatment with LPS and $3 \mathrm{~h}$ of high tidal volume ventilation (group IV). Bar length: $100 \mu \mathrm{m}$.

changes in BALF IL- $1 \beta$ protein concentrations were found in the four groups (Fig. 5C).

Histologic quantification of inflammation. Although the inflammation score was increased in both ventilation groups (Groups II and IV) compared with the nonventilation groups (Groups I and III), only the difference between Groups III and IV reached significance (Fig. 6A). The histologic changes in the lungs of Group IV animals showed a clear trend to hyperinflation with larger airspaces and attenuated septa. Furthermore, there were scattered multi-focal aggregates of inflammatory cells and amorphous eosinophilic material within the airspaces suggestive of lung injury.

\section{DISCUSSION}

Mechanical ventilation and high concentrations of oxygen applied to immature lungs of premature babies are known risk factors for the development of BPD (23). Risk is enhanced when inflammation/infection is associated e.g., due to acute or chronic chorioamnionitis or postnatal infection $(2,24)$. The goal of this study was to use a newborn rat model of alveolar development to test the hypothesis, that pre-existing systemically induced inflammation would modify the cytokine response to high tidal volume ventilation (HTVV) in lungs undergoing alveolarization. We first exposed the newborn rats to LPS and $24 \mathrm{~h}$ later after the initial inflammatory response has subdued the rats were subjected to HTVV. Our findings demonstrate that newborn rat lungs which are in saccular stage corresponding to the lung development of preterm patients show a marked increase in proinflammatory cytokine (IL-6, IL-1 $\beta$ ) and chemokine (CXCL2) mRNA expression in response to a relatively short duration of mechanical ventilation. The combination with a systemically induced inflammation further enhances the gene expression of IL- $1 \beta$ and IL-6.

Mechanical stress applied in vitro to alveolar epithelial cells and alveolar macrophages has been shown to increase the expression of a number of cytokines and chemokines, including IL-6, IL-8, IL- $1 \beta$, and TNF- $\alpha$ (25). In several adult animal models an increased expression of proinflammatory cytokines/ chemokines was demonstrated after mechanical ventilation, especially when high tidal volumes were used (26-29). Al- 
though immature lungs were shown to be less susceptible to high tidal volumes than adult lungs $(16,20)$, a marked increase of proinflammatory mediator expression was observed when newborn animals (16) and infants $(30,31)$ were exposed to mechanical ventilation. Bacterial products like lipopolysaccharide (LPS) also have the ability to induce a proinflammatory cytokine/chemokine response. Alveolar macrophages stimulated by addition of LPS to the cell culture medium express IL-8 (32). Inhalation of LPS induces a massive neutrophil influx together with a strong expression of proinflammatory cytokines/chemokines in the adult lung $(33,34)$. Several studies have shown that the combination of HTVV with another lung injury amplifies the inflammatory response in the adult lung. Gurkan et al. (12) showed that $4 \mathrm{~h}$ of ventilation with an elevated tidal volume $(17 \mathrm{~mL} / \mathrm{kg})$ after induction of lung injury with hydrochloric acid resulted in massive proinflammatory mediator expression in adult mouse lungs. Ventilation alone with smaller tidal volumes $(6 \mathrm{~mL} / \mathrm{kg})$ did not change the IL- 6 concentration in the adult murine lung, but ventilation of preinjured lungs showed a 4-5-fold increase in IL-6 content in lung tissue. Additionally, the combination of ventilation with pre-existing lung injury induced massive lung injury represented by pulmonary edema and an influx of inflammatory cells in the BALF of the mice (12). Tremblay et al. (11) demonstrated that in healthy adult rat lungs the proinflammatory cytokine expression was changed when HTVV was superimposed on a systemic inflammatory process. CXCL2 (GRO2/ MIP2) content increased significantly in BALF when HTVV was applied with pre-existing systemic inflammation (11). In the present study we used a relatively low dose of systemic LPS (3 $\mathrm{mg} / \mathrm{kg}$ ip), Tremblay et al. created sepsis using a high dose of systemically administered LPS (20 mg/kg IV) (11). However, both studies suggest that the combination of pre-existing systemic inflammation and HTVV increases cytokine expression in a synergistic way. This observation is further supported by a recent study of Altemeier et al. (13) who also found a synergistic effect of mechanical ventilation and systemic inflammation on cytokine expression in the lungs of adult rabbits.

Besides the increased risk for ventilator-associated lung injury, the lungs of premature infants exposed to the combination of inflammation and mechanical ventilation are also at higher risk of developing bronchopulmonary dysplasia (BPD) $(2,3)$. Histologically the lungs of these babies are characterized by less numerous but larger alveoli, aberrant vascularization and increased fibrosis compared with the airspaces of normal term babies (35). To explore potential long term effects of HTVV and systemic inflammation on alveolarization and vascularization, we evaluated mRNA expression of different proteins known to be associated with these developmental processes (see for review (22)). However, gene expression of T1 $\alpha$, TNC, tropoelastin, VEGF, and VEGFR2 were not affected by the various treatments. It is likely that the $3 \mathrm{~h}$ duration of injury was too short to see an effect on the expression of any of these proteins.

There is some evidence that prolonged and increased proinflammatory cytokine/chemokine levels in newborn lung may play a role in the disruption of normal alveolar and vascular formation seen in BPD. First, high levels of intra-amniotic
IL-1 leads to prolonged pulmonary inflammation and accelerated maturation (36) and injection of IL-1 in preterm lambs resulted in BPD like lesions with fewer but enlarged alveoli (37). Secondly, IL-8 is known to enhance angiogenesis by a mitogenic effect on endothelial cells (38). Blocking the excessive production of chemokines of the IL-8 family was shown to inhibit aberrant tumor angiogenesis (39). Increased Tolllike receptor signaling due to intra-amniotic LPS exposure reduces the expression of VEGF and VEGFR2 and impairs pulmonary vascular development (40). Thirdly, proinflammatory cytokines such as IL- $1 \beta$ and TNF- $\alpha$ not only induce pulmonary inflammation when overexpressed, but also play a role in pulmonary fibrosis (41).

In conclusion, similar to the adult nongrowing lung, superimposing positive pressure ventilation on a pre-existing inflammation in the growing lung undergoing alveolarization has a synergistic effect on the innate immune response. This increased gene expression of proinflammatory cytokines/ chemokines puts the developing lung at high risk to develop ventilator-associated lung injury.

\section{REFERENCES}

1. Smith VC, Zupancic JA, McCormick MC, Croen LA, Greene J, Escobar GJ, Richardson DK 2005 Trends in severe bronchopulmonary dysplasia rates between 1994 and 2002. J Pediatr 146:469-473

2. Watterberg KL, Demers LM, Scott SM, Murphy S 1996 Chorioamnionitis and early lung inflammation in infants in whom bronchopulmonary dysplasia develops. Pediatrics 97:210-215

3. Van Marter LJ, Dammann O, Allred EN, Leviton A, Pagano M, Moore M, Martin C 2002 Chorioamnionitis, mechanical ventilation, and postnatal sepsis as modulators of chronic lung disease in preterm infants. J Pediatr 140:171-176

4. Proost P, De Wolf-Peeters C, Conings R, Opdenakker G, Billiau A, Van DJ 1993 Identification of a novel granulocyte chemotactic protein (GCP-2) from human tumor cells. In vitro and in vivo comparison with natural forms of GRO, IP-10, and IL-8. J Immunol 150:1000-1010

5. McColm JR, McIntosh N 1994 Interleukin-8 in bronchoalveolar lavage samples as predictor of chronic lung disease in premature infants. Lancet 343:729

6. Ghezzi F, Gomez R, Romero R, Yoon BH, Edwin SS, David C, Janisse J, Mazor M 1998 Elevated interleukin-8 concentrations in amniotic fluid of mothers whose neonates subsequently develop bronchopulmonary dysplasia. Eur J Obstet Gynecol Reprod Biol 78:5-10

7. Bagchi A, Viscardi RM, Taciak V, Ensor JE, McCrea KA, Hasday JD 1994 Increased activity of interleukin-6 but not tumor necrosis factor-alpha in lung lavage of premature infants is associated with the development of bronchopulmonary dysplasia. Pediatr Res 36:244-252

8. Hoffmann E, Dittrich-Breiholz O, Holtmann H, Kracht M 2002 Multiple control of interleukin-8 gene expression. J Leukoc Biol 72:847-855

9. Shapiro L, Dinarello CA 1997 Hyperosmotic stress as a stimulant for proinflammatory cytokine production. Exp Cell Res 231:354-362

10. DeForge LE, Preston AM, Takeuchi E, Kenney J, Boxer LA, Remick DG 1993 Regulation of interleukin 8 gene expression by oxidant stress. J Biol Chem 268:25568-25576

11. Tremblay L, Valenza F, Ribeiro SP, Li J, Slutsky AS 1997 Injurious ventilatory strategies increase cytokines and c-fos m-RNA expression in an isolated rat lung model. J Clin Invest 99:944-952

12. Gurkan OU, O’Donnell C, Brower R, Ruckdeschel E, Becker PM 2003 Differential effects of mechanical ventilatory strategy on lung injury and systemic organ inflammation in mice. Am J Physiol Lung Cell Mol Physiol 285:L710-L718

13. Altemeier WA, Matute-Bello G, Frevert CW, Kawata Y, Kajikawa O, Martin TR, Glenny RW 2004 Mechanical ventilation with moderate tidal volumes synergistically increases lung cytokine response to systemic endotoxin. Am J Physiol Lung Cell Mol Physiol 287:L533-L542

14. Burri PH 1997 Structural aspects of prenatal and postnatal development and growth of the lung. In: McDonald JA (ed) Lung growth and development. Marcel Dekker, New York, pp 1-35.

15. Volgyesi GA, Tremblay LN, Webster P, Zamel N, Slutsky AS 2000 A new ventilator for monitoring lung mechanics in small animals. J Appl Physiol 89:413-421

16. Copland IB, Martinez F, Kavanagh BP, Engelberts D, McKerlie C, Belik J, Post M 2004 High tidal volume ventilation causes different inflammatory responses in newborn versus adult lung. Am J Respir Crit Care Med 169:739-748

17. Livak KJ, Schmittgen TD 2001 Analysis of relative gene expression data using real-time quantitative PCR and the 2(-Delta Delta C(T)) Method. Methods 25:402408 
18. Tsuchida S, Engelberts D, Roth M, McKerlie C, Post M, Kavanagh BP 2005 Continuous positive airway pressure causes lung injury in a model of sepsis. Am J Physiol Lung Cell Mol Physiol 289:L554-L564

19. Chan A, Jayasuriya K, Berry L, Roth-Kleiner M, Post M, Belik J 2005 Volutrauma Activates the Clotting Cascade in the Newborn but not Adult Rat. Am J Physiol Lung Cell Mol Physiol 290:L754-L760

20. Kornecki A, Tsuchida S, Ondiveeran HK, Engelberts D, Frndova H, Tanswell AK, Post M, McKerlie C, Belik J, Fox-Robichaud A, Kavanagh BP 2005 Lung development and susceptibility to ventilator-induced lung injury. Am J Respir Crit Care Med 171:743-752

21. Tsuchida S, Engelberts D, Peltekova V, Hopkins N, Frndova H, Babyn P, McKerlie C, Post M, McLoughlin P, Kavanagh BP 2006 Atelectasis causes Alveolar Injury in Non-Atelectatic Lung Regions. Am J Respir Crit Care Med 174:279-289

22. Roth-Kleiner M, Post M 2005 Similarities and dissimilarities of branching and septation during lung development. Pediatr Pulmonol 40:113-134

23. Jobe AH, Bancalari E 2001 Bronchopulmonary Dysplasia. Am J Respir Crit Care Med 163:1723-1729

24. Speer CP 2006 Inflammation and bronchopulmonary dysplasia: A continuing story. Semin Fetal Neonatal Med 11:354-362

25. Pugin J, Dunn I, Jolliet P, Tassaux D, Magnenat JL, Nicod LP, Chevrolet JC 1998 Activation of human macrophages by mechanical ventilation in vitro. Am J Physiol 275:L1040-L1050

26. Belperio JA, Keane MP, Burdick MD, Londhe V, Xue YY, Li K, Phillips RJ, Strieter RM 2002 Critical role for CXCR2 and CXCR2 ligands during the pathogenesis of ventilator-induced lung injury. J Clin Invest 110:1703-1716

27. Wilson MR, Choudhury S, Goddard ME, O'Dea KP, Nicholson AG, Takata M 2003 High tidal volume upregulates intrapulmonary cytokines in an in vivo mouse model of ventilator-induced lung injury. J Appl Physiol 95:1385-1393

28. Copland IB, Kavanagh BP, Engelberts D, McKerlie C, Belik J, Post M 2003 Early changes in lung gene expression due to high tidal volume. Am J Respir Crit Care Med 168:1051-1059

29. Chu EK, Whitehead T, Slutsky AS 2004 Effects of cyclic opening and closing at low- and high-volume ventilation on bronchoalveolar lavage cytokines. Crit Care Med 32:168-174

30. Schultz C, Tautz J, Reiss I, Moller JC 2003 Prolonged mechanical ventilation induces pulmonary inflammation in preterm infants. Biol Neonate 84:64-66
31. Cao L, Liu C, Cai B, Jia X, Kang L, Speer CP, Sun B 2004 Nuclear factor-kappa B expression in alveolar macrophages of mechanically ventilated neonates with respiratory distress syndrome. Biol Neonate 86:116-123

32. Lafleur RL, Abrahamsen MS, Maheswaran SK 1998 The biphasic mRNA expression pattern of bovine interleukin-8 in Pasteurella haemolytica lipopolysaccharidestimulated alveolar macrophages is primarily due to tumor necrosis factor alpha. Infect Immun 66:4087-4092

33. Ulich TR, Guo K, Yin S, del Castillo J, Yi ES, Thompson RC, Eisenberg SP 1992 Endotoxin-induced cytokine gene expression in vivo. IV. Expression of interleukin-1 alpha/beta and interleukin-1 receptor antagonist mRNA during endotoxemia and during endotoxin-initiated local acute inflammation. Am J Pathol 141:61-68

34. Johnston CJ, Finkelstein JN, Gelein R, Oberdorster G 1998 Pulmonary cytokine and chemokine mRNA levels after inhalation of lipopolysaccharide in C57BL/6 mice. Toxicol Sci 46:300-307

35. Coalson JJ 2003 Pathology of new bronchopulmonary dysplasia. Semin Neonatol 8:73-81

36. Willet KE, Kramer BW, Kallapur SG, Ikegami M, Newnham JP, Moss TJ, Sly PD, Jobe AH 2002 Intra-amniotic injection of IL-1 induces inflammation and maturation in fetal sheep lung. Am J Physiol Lung Cell Mol Physiol 282:L411-L420

37. Willet KE, Jobe AH, Ikegami M, Newnham J, Brennan S, Sly PD 2000 Antenatal endotoxin and glucocorticoid effects on lung morphometry in preterm lambs. Pediatr Res 48:782-788

38. He T, Peterson TE, Katusic ZS 2005 Paracrine mitogenic effect of human endothelial progenitor cells: role of interleukin-8. Am J Physiol Heart Circ Physiol 289:H968H972

39. Keshamouni VG, Arenberg DA, Reddy RC, Newstead MJ, Anthwal S, Standiford TJ 2005 PPAR-gamma activation inhibits angiogenesis by blocking ELR + CXC chemokine production in non-small cell lung cancer. Neoplasia 7:294-301

40. Kallapur SG, Bachurski CJ, Le Cras TD, Joshi SN, Ikegami M, Jobe AH 2004 Vascular changes after intra-amniotic endotoxin in preterm lamb lungs. Am J Physiol Lung Cell Mol Physiol 287:L1178-L1185

41. Lundblad LK, Thompson-Figueroa J, Leclair T, Sullivan MJ, Poynter ME, Irvin CG, Bates JH 2005 Tumor necrosis factor-alpha overexpression in lung disease: a single cause behind a complex phenotype. Am J Respir Crit Care Med 171: $1363-1370$ 